\title{
Gastronomia sustentável: aproveitamento da polpa de coco verde como alternativa de geração de renda
}

\author{
Caroline Brasil Lopes a; \\ Ingrid Conceição Dantas Guerra b; \\ Maria Gorette de Queiroz Oliveira c; \\ Erika Vanessa dos Santos Brito d
}

\section{RESUMO}

A Gastronomia Sustentável se reporta à sustentabilidade na agricultura, às políticas e práticas que levem ao desenvolvimento rural mais igualitário e ambientalmente sadio. Ela também tem a ver com formas de gerenciar e controlar os resíduos e sua reciclagem. É nesta vertente que esta proposta se encaixa, propondo-se a promover o aproveitamento da polpa do coco verde e qualificar para o mercado de trabalho, pessoas em situação de vulnerabilidade social. Foram desenvolvidas seis oficinas sendo a primeira de acolhimento e boas práticas e nas demais foram desenvolvidos espumante, compota, mousse, pudim, picolé utilizando-se a polpa do coco verde. As ações desenvolvidas promoveram a qualificação dos alunos envolvidos além de difusão das técnicas para desenvolvimento de produtos elaborados com a polpa do coco verde, proporcionando aos mesmos a possibilidade de incrementar a renda. $O$ desenvolvimento dos produtos também se apresenta como uma alternativa à redução do desperdício da polpa do coco verde e consequentemente ao seu uso sustentável.

\section{Palavras-chave}

Eco-Gastronomia

Sustentabilidade

Vulnerabilidade Social 


\section{INTRODUÇÃo}

Cultura típica de clima tropical, o coqueiro vem sendo cultivado em cerca de 90 países. No Brasil, o cultivo do coco se desenvolve principalmente ao longo do litoral, sendo encontrado em áreas desde o Estado do Pará até o Espírito Santo. As estatísticas atuais demonstram que o Brasil possui mais de 266 mil hectares implantados com a cultura, praticamente em quase todas as Unidades da Federação (Soares, 2014).

Os produtos provenientes do coco verde ou maduro são amplamente utilizados e comercializados, sendo os principais a polpa e o óleo, além de ácido láurico, leite de coco, fibra, farinha e água de coco. Aplicações desses produtos incluem alimentos, ração animal, sínteses industriais, sabões, detergentes e cosméticos (Almeida et al., 2006).

O fruto é uma drupa fibrosa. O epicarpo é uma película fina e lisa que envolve externamente o fruto, com coloração variável de verde a marrom. O mesocarpo, caracterizado por uma camada bastante grossa e fibrosa, torna-se matéria-prima com aproveitamento industrial variado, e o endocarpo, lenhoso, duríssimo, de coloração escura é utilizado com fins industrial e artesanal. Entre o endocarpo e o endosperma, existe uma fina camada de coloração marrom (tegumento), aderida fortemente ao albúmen sólido que constitui a polpa (Benassi et al., 2007).

A polpa do coco verde é comestível, porém o consumo do fruto in natura limita-se a água. Apresentando características diferentes da polpa do coco maduro, que tem utilização tanto para uso culinário quanto para produtos industrializados, a polpa do coco verde, juntamente com a casca, é considerada resíduo para descarte (Santana, 2012). A polpa de coco do coqueiro anão contém os ácidos graxos saturados cáprico, caprílico, cáproico, laúrico, mirístico, palmítico e esteárico; e os insaturados oléico e linoléico.

Apenas os teores do ácido laúrico são mais elevados, chegando em média a 38,1\% aos 6 meses e 49,6\% aos 12 meses, conforme analisado por Aragão et al. (2005). Ainda neste estudo, os autores avaliaram os teores de gordura $(\mathrm{g} / 100 \mathrm{~g})$, da polpa dos frutos de seis cultivares de coqueiro anão e concluíram que há um acréscimo destes teores até 11 meses de idade do fruto e um decréscimo na idade de 12 meses, independente da cultivar.
Segundo Andrade et al. (2004), nas cidades litorâneas e turísticas do Brasil, podem ser encontradas grandes quantidades de coco verde descartados diariamente por comerciantes informais e por empresas que comercializam a parte comestível ou a água desse fruto. Isso tem provocado um significativo aumento nos serviços municipais de coleta, transporte e deposição de lixo em função, principalmente, do grande volume que representa.

A palavra sustentabilidade, conforme Ehlers (2005), tem origem no latim sus-tenere, cujo significado é suportar ou manter. A partir da década de 1970, o tema ganhou dimensões ambientais, econômicas, financeiras, sociais, políticas, educacionais dentre outras, inclusive a gastronômica. De acordo com esse autor (2005), a sustentabilidade ambiental envolve a interação entre crescimento populacional, uso de recursos e pressão sobre o meio ambiente. Tem sido discutida a partir de diferentes abordagens: a ecológica, a da crítica à tecnologia, o ecodesenvolvimento, e as que pregam o não crescimento ou redução do crescimento econômico.

O autor lembra que essa noção abriga concepções políticas e propostas de desenvolvimento diferentes e até opostas. Há os que propõem simples ajustes no modelo vigente de desenvolvimento e outros que demandam mudanças estruturais nos padrões de produção e de consumo das sociedades. O conceito de sustentabilidade é alvo de debates por ser uma problemática complexa e fortemente dependente do contexto social.

A ecogastronomia se reporta à sustentabilidade na agricultura, às políticas e práticas que levem ao desenvolvimento rural mais igualitário e ambientalmente sadio. Isso significa ser ecologicamente equilibrada, economicamente viável, socialmente justa, humana e adaptativa. Nessa plataforma política se incluem a segurança alimentar, a produtividade e a qualidade de vida.

Ela também tem a ver com formas de gerenciar e controlar os resíduos e sua reciclagem, de combater os grandes prejuízos ambientais, sanitários e financeiros de descartes inadequados sem a determinação prévia para a disposição final ou armazenamentos temporários. Resíduos orgânicos podem ser reprocessados para a alimentação animal e compostagem, já os resíduos inorgânicos podem beneficiar cooperativas de reciclagem (Campolina e Machado, 2015).

Desenvolvimento local, sob a perspectiva da gastronomia sustentável, significa efetividade de políticas públicas de redução das desigualdades 
sociais, que integrem dimensões econômicas, sociais, culturais e ambientais, nos níveis da produção, distribuição e consumo. Significa adoção de tecnologias limpas e o engajamento da população em práticas de sustentabilidade.

O grande desafio encontra-se na efetivação do consumo sustentável, sobretudo nos países ricos, pois o que está em jogo são as possibilidades de compatibilizar necessidades humanas, sempre crescentes, e o uso de recursos naturais dentro dos limites ecológicos do planeta. O consumo sustentável, porém, em todo o mundo, ainda é uma prática de minorias e não tem sido tratado em sua complexidade por toda a sociedade, o que Gastronomia sustentável, formação do gastrônomo e desenvolvimento local representa um grande desafio para a concretização dos princípios da ecoeficiência.

Esse conceito envolve produtos e práticas gastronômicas e culinárias sustentados por tecnologia limpa, de redução do desperdício e aproveitamento máximo dos recursos (Campolina e Machado, 2015).

É nesta vertente que esta proposta se encaixa, propondo-se a dentro dos princípios da ecogastronomia desenvolver tecnologias e novos produtos a partir da polpa do coco verde, e difundir os produtos gerados em cozinhas comunitárias do município de João Pessoa como fator gerador de renda para pessoas em situação de vulnerabilidade social.

\section{MetOdologia}

\section{Obtenção da matéria-prima}

Para a obtenção da matéria-prima inicialmente foi feito um contato com os vendedores informais de água de coco no município de João Pessoa - PB. Os pesquisadores ficaram nos pontos dotados de sacos limpos e coletaram os cocos que foram abertos e a água foi retirada e colocada em garrafas de polietileno para comercialização em litros de modo a garantir a segurança alimentar da matéria-prima (não houve consumo direto com o canudo).

Os sacos com os cocos foram colocados em caixas isotérmicas e conduzidos até o Laboratório de Processamento de Alimentos do Centro de Tecnologia e Desenvolvimento Regional da Universidade Federal da Paraíba (CTDR/UFPB). Em ambiente laboratorial o albúmen comestível (polpa de coco verde) foi cuidadosamente retirada do endocarpo, embalada e congelada até o momento do uso. Antes da utilização, alíquotas das polpas foram submetidas a análises microbiológicas para atestar a segurança da matéria-prima.

\section{Desenvolvimento das receitas e elaboração das cartilhas}

Utilizando a polpa do coco verde, foram realizados testes em laboratório para definir as receitas que fariam parte da cartilha. As receitas deveriam aliar: facilidade de execução, ser sensorialmente agradáveis e ser de baixo custo para otimizar os lucros de quem as produzisse.

Após diversos ensaios pilotos definiu-se cinco receitas. Com as receitas definidas, a cartilha foi montada contendo a ficha técnica de cada receita, lista de ingredientes e utensílios, custo e valor estimado de venda além de orientação sobre boas práticas de fabricação tudo feito em linguagem simples e de fácil entendimento.

\section{Oficinas de difusão de tecnologias a partir do coco verde}

A partir da parceria firmada com a Prefeitura Municipal de João Pessoa, por meio da Diretoria de Trabalho, Renda e Economia Solidária, as oficinas foram realizadas em duas cozinhas comunitárias do município (Bela Vista e Timbó), com os beneficiários selecionados pelo Centro de Referência de Assistência Social - CRAS e Programa de Saúde da Família de cada comunidade.

A seleção dos usuários para as oficinas foi feita com base no interesse e disponibilidade de tempo. Cada oficina durou em média 4 horas e os envolvidos foram certificados ao final de cada uma delas. Em cada cozinha foram realizadas seis oficinas sendo uma de acolhimento e boas práticas para manipulação de alimentos e as outras cinco referentes às receitas das cartilhas. Após 0 encerramento das oficinas foi realizado um encontro de avaliação das ações pelos participantes.

\section{RESULTADOS}

Para compor a cartilha do projeto foram desenvolvidas seis receitas com coco verde. No Quadro 1 estão descritas as receitas desenvolvidas conforme encontram-se no material divulgado (Figura 1). 
Quadro 1 - Receitas desenvolvidas utilizando a polpa do coco verde

\begin{tabular}{|c|c|c|c|}
\hline RECETTA & INGREDIENTES & MODO DE PREPARO & RENDIMENTO \\
\hline Picolé de coco verde & $\begin{array}{l}\text { Polpa de } 5 \text { cocos verdes } \\
1 \text { caixa de leite condensado } \\
2 \text { xicaras de açúcar } \\
1 \text { litro de àgua potável }\end{array}$ & $\begin{array}{l}\text { Bater tudo em liquidificadoror doméstico, } \\
\text { acondicionar em formas para picolée ou } \\
\text { saquinhos e colocar para congelar. }\end{array}$ & 25 unidades \\
\hline Compota de coco verde & $\begin{array}{l}\text { Polpa de } 6 \text { cocos bem verdes } \\
2 \text { 2icaras de a aucar } \\
1 \text { xicara de aguar }\end{array}$ & $\begin{array}{l}\text { Colocar a água e o açúcar em uma panela até } \\
\text { formar uma calda. Adicionar os cocos verdes }\end{array}$ & 1 vidro de 800 g. \\
\hline Mousse de coco verde & $\begin{array}{l}\text { Polpa de } 5 \text { cocos verdes } \\
1 \text { caixa de leite condensado } \\
\text { A mesma medida da caixinha de água de coco } \\
1 \text { caixa de creme de leite } \\
1 \text { envelope de gelatina em pó sem sabor. }\end{array}$ & $\begin{array}{l}\text { Preparar a gelatina (com água fria é água } \\
\text { quente conforme orientaço do rótulo. } \\
\text { Bater todos os ingredientes ea gelatina em } \\
\text { liquidificicaror. } \\
\text { Levar à geladeira para gelar. }\end{array}$ & 10 a 12 porçōes \\
\hline Pudim de coco verde & $\begin{array}{l}\text { Polpa de cinco cocos } \\
1 \text { caixa de leite condensado. } \\
\text { A messma medida da caixa de água de coco. } \\
1 \text { caixa de creme de leite } \\
1 \text { xicara de aquicar } \\
4 \text { ovos. }\end{array}$ & $\begin{array}{l}\text { Fazer o caramelo em uma forma com o açúcar } \\
\text { e reservar. } \\
\text { Bater todos os os ingredientes no liquidificador e } \\
\text { adicionar na forma caramelizada. } \\
\text { Fazer o cozimentio em banho maria por uma } \\
\text { hora ou até completo cozimento. }\end{array}$ & 10 a 12 porç̧̋es \\
\hline Espumante de coco verde & $\begin{array}{l}\text { Polpa de } 1 \text { coco verde } \\
400 \mathrm{~mL} \text { de água de coco } \\
5 \text { colheres de leite condensado. } \\
\text { Gelo a gosto }\end{array}$ & Bater tudo no liquidificador e servir. & $\begin{array}{l}2 \text { copos de } \\
300 \mathrm{ml}\end{array}$ \\
\hline
\end{tabular}

Fonte: os autores (2019).

Analisando o Quadro 1 pode-se constatar que todas as receitas desenvolvidas são de fácil preparo e utilizam quantidades significativas de polpa de coco verde, o que se torna de fundamental relevância tendo em vista que quanto mais polpa utilizada por receita, menor será o desperdício de matéria-prima e maior o aproveitamento do coco verde. Em relação a utensílios a maioria utiliza liquidificador e fogão doméstico.

Figura 1 - Cartilha e certificado conferido aos participantes das oficinas

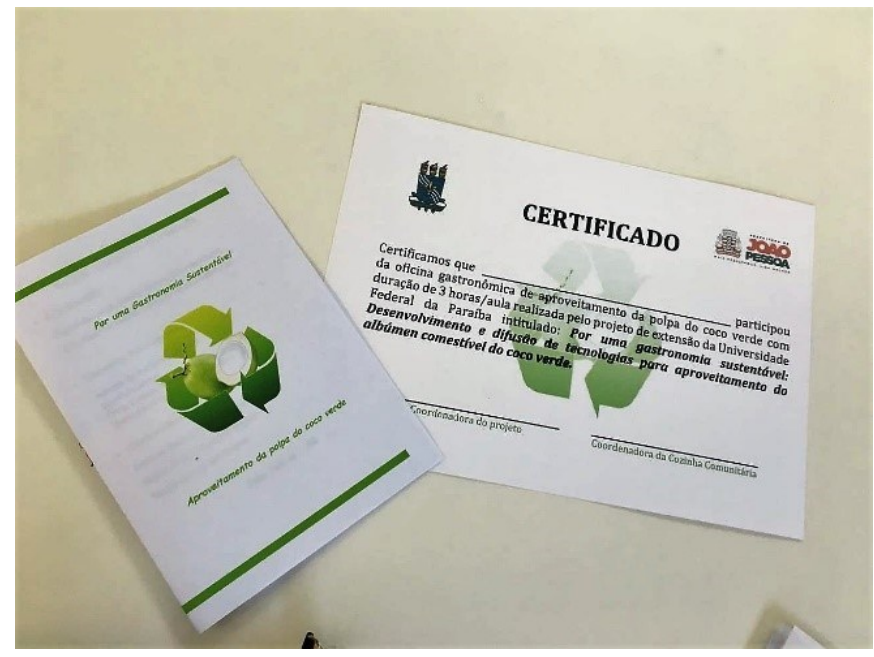

Fonte: os autores (2019).

Além das receitas a cartilha contém informações acerca da construção de um "porta chaves da alimentação segura", sendo trabalhado nesta oficina de forma lúdica os aspectos necessários de higiene do manipulador, dos utensílios e dos ingredientes, além de aspectos relacionados à qualidade da água e as temperaturas de conservação, de modo a promover a segurança alimentar e nutricional.

Também faz parte da cartilha, o custo da receita e a estimativa de lucro do rendimento de cada uma delas (Quadro 2).
O produto de custo mais baixo a ser produzido é a compota de coco verde, seguida do espumante e do picolé. O picolé além de estar entre os mais baixos custos de produção é o que fornece a maior perspectiva de lucro se vendidas todas as unidades produzidas. A compota mostra-se como alternativa bastante interessante uma vez que é necessário vender apenas 5 unidades para atingir a lucratividade do picolé por exemplo.

Quadro 2 - Quebra-cabeça nº 01

\begin{tabular}{|l|l|l|l|}
\hline RECEITA & $\begin{array}{l}\text { Custo de } \\
\text { produção }\end{array}$ & Custo por porção & Estimativa de lucro \\
\hline $\begin{array}{l}\text { Picolé de coco } \\
\text { verde }\end{array}$ & $R \$ 4,95$ & $R \$ 2,00$ & $R \$ 45,95$ \\
\hline $\begin{array}{l}\text { Compota de coco } \\
\text { verde }\end{array}$ & $R \$ 0,90$ & $R \$ 12,00$ & $R \$ 11,10$ \\
\hline $\begin{array}{l}\text { Mousse de coco } \\
\text { verde }\end{array}$ & $R \$ 9,10$ & $R \$ 4,00$ & $R \$ 30,80$ \\
\hline $\begin{array}{l}\text { Pudim de coco } \\
\text { verde }\end{array}$ & $R \$ 9,40$ & $R \$ 4,00$ & $R \$ 30,6$ \\
\hline $\begin{array}{l}\text { Espumante de } \\
\text { coco verde }\end{array}$ & $R \$ 2,94$ & $R \$ 10,00$ & $R \$ 17,06$ \\
\hline
\end{tabular}

Fonte: autores (2019).

O pudim mostra-se como receita de maior custo de produção pois reúne maior quantidade de ingredientes além do dispêndio de gás para o cozimento. Mesmo sendo o maior, o custo de produção de todas as receitas é baixo e a perspectiva de lucro mostra-se como alternativa promissora para geração de renda em comunidades socialmente vulneráveis.

O Programa de Incentivo à Instalação de Cozinhas Comunitárias faz parte do conjunto de ações governamentais voltadas para segurança alimentar e tem como objetivo incentivar e apoiar a implantação de pequenas unidades de produção de refeições. O programa pretende estabelecer uma rede de proteção alimentar para os segmentos populacionais vulneráveis à fome, baseada nas estratégias de ampliação da oferta de refeições nutricionalmente balanceadas e inclusão social produtiva (BRASIL, 2006; BANDONI et al., 2010).

Assim, o objetivo da política pública é não somente o fornecimento das refeições para usuários em situação de vulnerabilidade mas também promover qualificação de modo que por meio da geração de renda a realidade da comunidade seja modificada.

As oficinas realizadas na Cozinha Comunitária Bela Vista e na Cozinha Comunitária do Timbó foram 
ministradas por alunos dos cursos de Gastronomia e Nutrição da UFPB (Figura 2).

Figura 2 - Oficinas teórico-práticas realizadas na Cozinha Comunitária Bela Vista - João Pessoa -PB

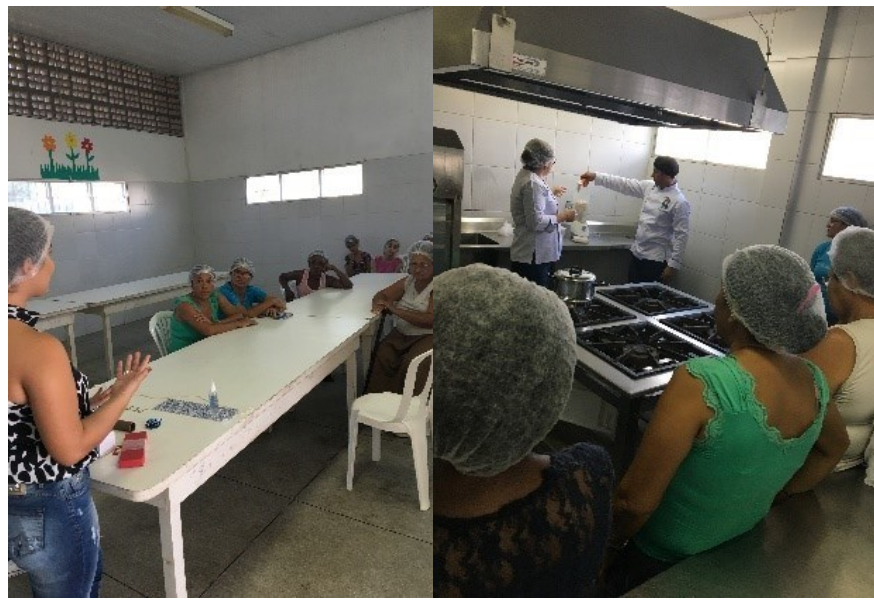

Fonte: autores (2019).

Todas as oficinas tiveram caráter teórico-prático e foram conduzidas de forma lúdica e em linguagem apropriada sempre destacando a importância de levar adiante o conhecimento obtido nos dias de oficina e da possibilidade de melhoria na condição de vida dos envolvidos caso comercializassem os produtos. Em cada uma das cozinhas foram executadas todas as oficinas da cartilha (Figura 3) e ao final essas preparações foram degustadas pelos participantes.

Figura 3 - Preparações desenvolvidas a partir do aproveitamento do coco verde (pudim, picolé, mousse e compota)

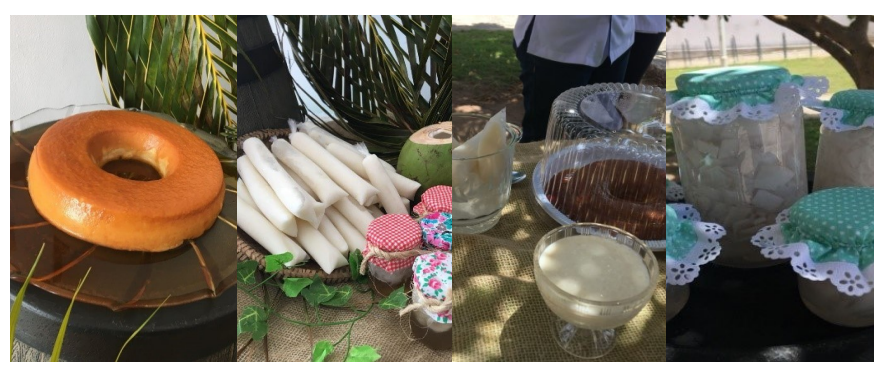

Fonte: autores (2019).

Após o encerramento das oficinas procedeu-se a um período de dois meses e então foi feito um encontro de avaliação com as pessoas beneficiadas pelas oficinas das comunidades Bela Vista e Timbó. No encontro, foi feita uma mesa redonda e questionado se alguém tinha executado alguma das receitas e tentado comercializar.

Alguns mencionaram ter executado a receita da compota por não utilizar muitos ingredientes, mas mencionaram não conseguir vender na comunidade. Outras falas mencionaram a falta de recursos para a compra de insumos. Com base neste encontro de avaliação pesquisadores e Prefeitura Municipal de João Pessoa se reuniram para analisar de que formas as dificuldades mencionadas poderiam ser sanadas.

Os encaminhamentos deste encontro foram: buscar o "Banco Cidadão" para financiar pequenas quantias para que os que tem interesse possam comprar os ingredientes para começar, busca de parceiros na rede hoteleira do município que possa adquirir a produção inicialmente e oferecer aos hóspedes na prerrogativa da solidariedade e sustentabilidade.

O projeto continua em execução, para alcançar as demais cozinhas do município e montar um estudo piloto para que trabalhem na perspectiva da cooperação.

\section{Aplicabilidade do conhecimento científico no mercado}

Com o devido investimento, os produtos desenvolvidos a partir da polpa do coco verde podem ser produzidos e comercializados em larga escala mediante um sistema de cooperativismo. Devido a facilidade de execução, o baixo custo de produção e matéria prima de grande aceitação pela população, não haveriam grandes barreiras quando da sua inserção no mercado.

Aliando esse fator a oportunidade de reaproveitamento de uma matéria prima que seria descartada, esses novos produtos chegariam aos consumidores com 0 selo de sustentabilidade, o que pode apresentar-se como ponto positivo em um mercado que preza cada dia mais para a preservação do meio ambiente e reaproveitamento de matérias-primas naturais.

\section{CONSIDERAÇÕES FINAIS}

As ações desenvolvidas promoveram a qualificação dos alunos envolvidos quanto a Higiene e Manipulação de alimentos além de difusão das técnicas para desenvolvimento de produtos elaborados com a polpa do coco verde, proporcionando aos mesmos tanto a possibilidade de inserção no mercado de trabalho quanto o desenvolvimento dos produtos em ambiente doméstico, podendo incrementar a renda domiciliar a partir da venda dos produtos.

O desenvolvimento dos produtos também se apresenta como uma alternativa à redução do desperdício da polpa do coco verde e consequentemente ao seu uso sustentável. 


\section{REFERÊNCIAS}

Almeida, A. C. O. de; Loiola, C. M.; Aragão, W. M.; Freire, A. da C. (2006). Caracterização carpológica de frutos de cultivares de coqueiro anão amarelo de diferentes locais de Sergipe. Embrapa Comunicado Técnico, 60, Aracaju.

Andrade, A. M. de; Passos, P. R. de A.; Marques, L. G. da C.; Oliveira, L. B.; Vidaurre, G. B.; Rocha, J. das D. de S. (2004). Pirólise de resíduos do coco-da-baía (Cocos nucifera Linn) e análise do carvão vegetal. Revista Árvore, Viçosa, v. 28, n. 5, p. 707-714.

Aragão, W. M.; Cruz, E. M. de O.; Ribeiro, F. E.; Tupinambá, E. de A.; Tavares, M.; Pimentel, S. A.; Takemoto, E. (2005). Teor de gordura e composição de ácidos graxos em polpa de frutos de coqueiro anão em diferentes idades de maturação. In: Congresso Brasileiro De Plantas Oleaginosas, Óleos, Gorduras E Biodiesel, 2., 2005, Varginha. Anais... Lavras: Universidade Federal de Lavras. p. 615-618.

Bandoni, D. H.; Marchioni, D. M. L.; Brasil, B. G.; Figueiredo, I. C; Sarti, F. M. (2010). The program of incentives for installation of community cafeterias: evaluation of a brazilian public policy. Nutrire: rev. Soc. Bras. Alim. Nutr. = J. Brazilian Soc. Food Nutr., São Paulo, SP, v. 35, n. 1, p. 15-27.

Benassi, A. C.; Ruggiero, C.; Martins, A. B. G.; Alberto Da Silva, J. A. (2007). Caracterização biométrica de frutos de coqueiro, Cocos nucifera L. variedade anã-verde, em diferentes estádios de desenvolvimento. Revista Brasileiira de Fruticultura, Jaboticabal. v. 29, n. 2, p. 302-307.

Brasil. Ministério do Desenvolvimento Social e Combate a Fome. (2006). Manual de Implantação de Cozinhas Comunitárias [Internet]. Brasília (DF).

Campolina, R.M.; Machado, L.R.S. (2015). Gastronomia sustentável, formação do gastrônomo e desenvolvimento local. Competência, Porto Alegre, RS, v.8, n.2, p. 125-144.

Ehlers, E. (2005). A agricultura alternativa: uma visão histórica. Estudos Econômicos, São Paulo, v. 24, especial, p.231-262.

Santana, I. A. (2012). Avaliação química e funcional de polpa de coco verde e aplicação em gelado comestíve. $107 \mathrm{f}$. Dissertação (Mestrado em Engenharia de Processos Químicos e Bioquímicos) - Instituto Mauá de Tecnologia, São Caetano do Sul.

Soares, G.L. (2014). Aproveitamento da polpa de coco verde submetida ao congelamento rápido e lento. Dissertação (Mestrado em Ciências Agronômicas). Botucatu, São Paulo, UNESP. 